\title{
Parametric Performance of Ultra-light Gas Turbine Power Plant for Heavy Lift Multicopters Flight Systems Using Astra - Russian Aviation Engine Optimization Software
}

\author{
T. Aurthur Vimalachandran ${ }^{1}$, Andrey Yurievich Tkachenko ${ }^{1}$ and Viktor Nikolaevich Rybakov ${ }^{1}$ \\ ${ }^{1}$ Department of Theory of Aircraft Engine, Samara University, Samara, Russia.
}

\begin{abstract}
A detailed parametric analysis was performed on entire performance cycle model of micro gas turbine power plant. The parametric analysis was studied using Russian Software named ASTRA. Evaluation of parameters on both design and operation condition was performed. The parameters focused here are power output, compression work, specific fuel consumption and thermal efficiency. Various stages such as use of Intercooler, Pre-heater and their optimal influence on thermodynamics were performed. The task was to optimize the maximum output in free turbine power by simulating various cycles of compressor pressure ratios for centrifugal compressor, ambient temperature in various altitude; air- fuel mix ratio and turbine inlet temperature. The results are analysed and presented in this article, the Analysis known as on-design analysis. The compressor uses $66 \%$ of turbine work output. The research analysis focuses on reducing the use of power output by compressor and maximizes the power output by free turbine. The results could be summarized as increase in gas turbine thermal efficiency does not always improve the gas turbine efficiency. Optimum power increase of up to $3 \%$ was improved and improvement in fuel efficiency improved about $4 \%$.
\end{abstract}

\section{Introduction}

This article research was to optimize the theoretical and mathematical design for a lightweight Gas turbine for producing $8 \mathrm{~kW}$ of power. The system considers powering any heavy lifting drones that could lift $200 \mathrm{~kg}$ and produce about $600 \mathrm{~kg}$ of thrust. The Engine should produce minimum and stable output of $7 \mathrm{~kW}$ at all operating conditions. The Parametric Analysis must have an output of highly optimized low Temperature inlet to Turbine (TiT). Lightweight energy systems widely required for aviation industry. The aviation industry from Drones to UAV requires micro gas turbine to power all necessary systems and in great demand. A Gas turbine rating from $5 \mathrm{~kW}-50 \mathrm{~kW}$ has a CAGR growth of $8 \%$ and a market value of $\$ 150$ Million. These researched market values, obtained and extrapolated from the resources available at The European Turbine Network (ETN) and Gas Turbine Association (GTA). Engineers work to apply and solve technological problems using their knowledge and available materials for producing efficient, cost effective and reliable systems.

The last three decades witnessed large advancement for gas turbine technology. The research focused on

1. Increase in compressor pressure ratio,

2. Combustion techniques,

3. New materials.

The research focuses on investigation of theoretical limits for performances of the gas turbine used as power source for the drone based on the numerical simulation using computer-aided system ASTRA. The computeraided system ASTRA developed at the Samara University used for thermo-gas dynamics helps to investigate numerical analysis [1].

This research deals with the gas turbine efficiency. The Gas turbine efficiency focuses on Pressure ratio and Cycle Peak Temperature [2]. Researchers try to increase gas turbine efficiency using various techniques, for example: pre-heater, intercooler, bleed-out and more. In micro gas turbine, addition of such stages will increase the mass of the system. The intercooler stage reduces the consumption power of compressor [3]. The pre-heater reduces the fuel consumption in the combustion chamber. Mass is an important factor for Gas turbine and any addition of stage would have to provide vital significance to the engine efficiency. Physical limits of materials contribute to the work output. In this article, a parametric study for performances of lightweight gas turbine power plant was performed using Russian software ASTRA. The parameters investigated were ambient temperature, pressure ratio, turbine inlet-temperature, specific fuel consumption and air fuel ratio and their effects on overall engine efficiency. The research uses parametric analysis method to increase performance and efficiency of gas turbine engine.

In aviation industry, gas turbine power plant is the preferable power generation systems due to weight to power ratio. High heat loss results in huge thermal efficiency losses in gas turbine engines. Heat loss 
mitigation is the main concern of this paper. To create energy efficient system by conserving heat loss could be done by reduction of Temperature to turbine inlet (TiT). Transfer of waste heat energy to useful energy results in the improvements of overall efficiency of the engine. The heat energy, converted in following ways by regeneration and by preheater. The exhaust heat energy reutilized as preheater for the combustion system or regenerator in the free turbine section [4].

Around the heat range of $350-750^{\circ} \mathrm{C}$, found to be waste for a gas turbine. Many studies have been conducted to reuse/recover/optimize the heat to generate more power. Various proposals were made for using additional stages or hybrid systems to utilize this excess heat. However, this article deals with the use of minimum Temperature to turbine inlet (TiT) to avoid excess fuel to reduce waste heat.

\section{Parametric analysis and optimization methodologies}

This Virtual simulation acts as a cost-effective way to create robust designs and prototypes. Studying the engineering simulations by changing values provide insights on impacts of design. A model varying parameter simulated in many conditions help us investigate and multiple design criteria simultaneously performing various iterations. Evaluation of data in batches of even thousands can rapidly be investigated to explore best design. This evaluation process of design by varying parameters is Parametric Analysis. In any complex models, operating conditions, material, geometries or any related parameters are quantified for studying system overall functionality and behaviour. This process is handy even without any previous experience of developing such design. [5].

This method rejects the "guess and apply" approach for design configurations. The parametric studies allow sensitive analysis with different sets of parameters and boundary layer conditions. The procedures for Parametric Statistical Analysis rely on the preliminary assumptions and boundary layer conditions for forming shape of statistical distribution. This is compared with normal distributions such as mean and standard deviation for the various iterations and population counts. The table 1 depicts the difference between an optimization study and a parametric study.

In this parametric study, the airstream entering the gas turbine engine is studied at the compressor, engine core and for both the turbines all done simultaneously. The cycle analysis efficiency studies are applied to improve the performance and also to meet the initial requirements.

Table 1. Parametric analysis optimisation

\begin{tabular}{|c|c|c|}
\hline Differences & $\begin{array}{c}\text { Parametric } \\
\text { analysis }\end{array}$ & Optimization \\
\hline $\begin{array}{c}\text { Solving } \\
\text { Methodologies }\end{array}$ & $\begin{array}{c}\text { The user defines } \\
\text { the solving } \\
\text { scenario and } \\
\text { logical sequences. }\end{array}$ & $\begin{array}{c}\text { The process } \\
\text { works on } \\
\text { advanced } \\
\text { algorithm that } \\
\text { is used for }\end{array}$ \\
\hline
\end{tabular}

\begin{tabular}{|c|c|c|}
\hline & & $\begin{array}{l}\text { optimizations. } \\
\text { The results } \\
\text { could be either } \\
\text { stochastic or } \\
\text { deterministic. }\end{array}$ \\
\hline Solution Output & $\begin{array}{c}\text { The results are in } \\
\text { cloud pattern and } \\
\text { not refined set of } \\
\text { numbers. } \\
\text { The results are } \\
\text { post processed by } \\
\text { optimization } \\
\text { methodologies. }\end{array}$ & $\begin{array}{l}\text { The values that } \\
\text { are optimized } \\
\text { and satisfies } \\
\text { the initial } \\
\text { requirements. } \\
\text { The results are } \\
\text { compromised } \\
\text { final solutions. }\end{array}$ \\
\hline
\end{tabular}

Parametric cycle analysis of ideal gas turbine engine includes the following assumptions, to derive the performance of components.

- Engine components considered to be ideal

- The working fluid behaves as a perfect gas when $\mathrm{Cp}$ is constant.

- The engine performance trend analysis is investigated.

The performance of components is mainly determined with the following parameters.

- The specific heat varied in combination with various temperatures of fuel/air ratio.

- The components losses are optimized to realistic losses.

- Designation through engine figures of merit of various for various components sizing.

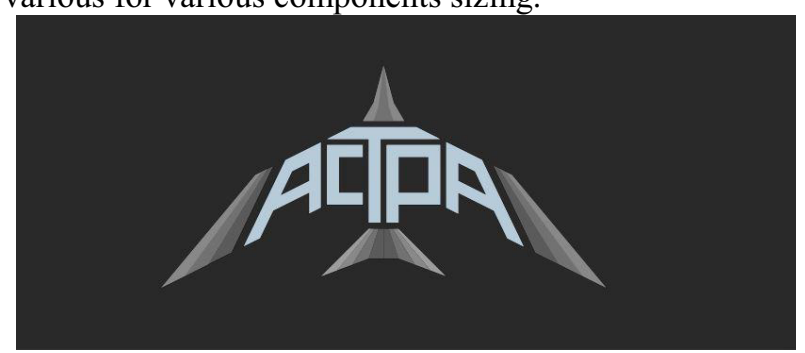

Figure 1. The name and the logo of the Russian software developed in the university used for Parametric analysis and optimization in this research (in English pronounced as ASTRA).

The computer-aided system ASTRA developed at the Samara University used for Parametric Analysis and optimization for the required gas turbine powerplant and the depiction of software as shown in figure 1.

Parametric Analysis of our Micro Gas turbine engine cycle analysis was performance for different engine cycles to predict and study their performance and their effects on losses in real conditions. One-dimensional flow was considered for performing variation of specific heats, components losses were considered at mass flow at various components. The exhaust pressure need not be equal to the atmospheric pressure.

\section{Requirements of the gas turbine power plants}

Delivery drones shall become widespread in the ten years. Many Industrial giants such as Amazon, Google, DHL, 
and Alibaba have been testing their in-house drone delivery systems. In the future drones have the potential to replace could truck transport system having a positive implication on energy consumption, public safety, and road congestion. The use of Drones for emergency and freight purposes could reduce the energy consumption in this field. Currently commercial technologies of multicopter do not have the lift capability of more than 15 $\mathrm{Kg}$ of using 8 rotors. The battery runs for maximum 15 mins under such load. The onboard batteries drain leading to very limited delivery ranges. Thus, a need of heavy lift muticopter studies arises.

A multicopter specified here needs to lift a mass of $200 \mathrm{~kg}$ and should be able to produce $400 \mathrm{~kg}$ of thrust for hovering capabilities. Additional requirements of the multicopter should be able to carry the payload to a distance of $300 \mathrm{~km}$ without refueling. The vehicle is expected to have a maximum speed of $145 \mathrm{~km} / \mathrm{s} . \quad 400 \mathrm{~kg}$ of lift thrust could be generated by using 8 motors of 4 $\mathrm{kW}$ each producing about $50 \mathrm{~kg}$ of thrust. The propeller size and the motor stator correlates to each other so specific iterations need to be performed. Apart from this, selection of motor also includes the factors such as weight efficiency power, and torque. However, the scope of this paper does not study or design the quadcopter. These performance requirements cannot be matched by an Electric Drones with current battery mass technologies, thus comparison studies of Gas turbine powered multicopter Vs Electric Gas turbine of same configuration cannot be performed.

The Speed of drone defined to be in the range of subsonic speed. The altitude of the flight has a maximum operational value of 5 kilometer; however, the analysis is performed at the sea level conditions. The table 2 shows the important assumptions and consideration required to develop a theoretical micro gas turbine for the multicopter. Advanced light weight turbine power systems should be highly efficient in terms of fuel mass to power ratio, environmental friendly, light weight, low maintenance and cost- effective. The gas turbine must incorporate advanced material for withstanding high temperatures without external cooling stations, however aerodynamic cooling is a progress in technology. The drone requires to power 8 motors each producing $15 \mathrm{~kg}$ of thrust has a rating of 5,000 watts. The Speed of drone defined to be in the range of subsonic speed. The altitude of the flight has a maximum operational value of 5 kilometer; however, the analysis is performed at the sea level conditions. The table 2 shows the important assumptions and consideration required to develop a theoretical micro gas turbine for the multicopter.

\section{Description of micro gas turbine power generator Schematic and station}

Modern and most widely used power generating techniques suited for various applications is a gas turbine power generator. Gas turbine Generator has an internal combustion that burns with mixture of Air and Fuel causing hot gas. This hot fluid spins a turbine to produce required power. The difference between gas turbine and piston engine is the continuous and non-continuous combustion methodology. To design any power systems, a prerequisite prophase design review is necessary. The studies define the operational requirement of the system. The Gas turbine power plant operates in the principle of Brayton cycle and a representation is shown in the figure 2.

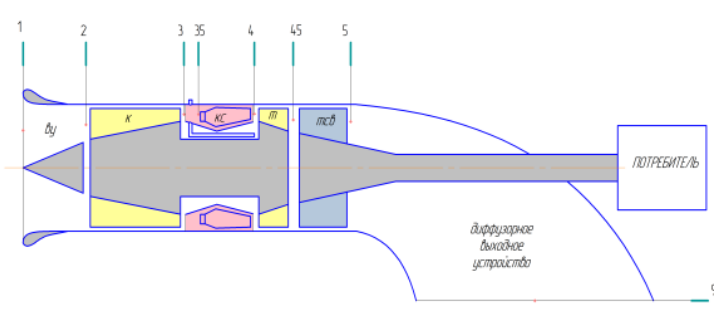

Figure 2. The model of the gas turbine powerplant is shown. The micro gas turbine powerplant has an Intake, Centrifugal compressor, Combustor, first turbine to run the compressor, free turbine connected to generator via shaft and exhaust.

Table 2. Gas turbine powerplant requirements.

\begin{tabular}{|c|c|c|}
\hline Requirement & Specification & Conversion \\
\hline $\begin{array}{c}\text { The multicopter } \\
\text { should be able to } \\
\text { lift a mass of } \\
200 \mathrm{~kg} .\end{array}$ & $\begin{array}{c}\text { To produce a } \\
\text { thrust of } 500 \mathrm{~kg} .\end{array}$ & $\begin{array}{c}\text { Requires } 8 \mathrm{~kW} \\
\text { of electric } \\
\text { power. }\end{array}$ \\
\hline $\begin{array}{c}\text { The multicopter } \\
\text { should be able to } \\
\text { fly at a ceiling } \\
\text { height of } 5 \mathrm{~km} \\
\text { altitude. }\end{array}$ & $\begin{array}{c}\text { Engine pressure } \\
\text { ratio conversion. }\end{array}$ & $\begin{array}{c}\text { A pressure } \\
\text { ration of } \\
\text { optimized } \\
\text { value needed } \\
\text { to be found. }\end{array}$ \\
\hline $\begin{array}{c}\text { The multicopter } \\
\text { should be able to } \\
\text { cover a distance } \\
\text { of 300 km. } \\
\text { without } \\
\text { refuelling. }\end{array}$ & $\begin{array}{c}\text { The power from } \\
\text { shaft is converted } \\
\text { to battery system. }\end{array}$ & $\begin{array}{c}\text { Continuous } \\
\text { output from } \\
\text { free turbine is } \\
\text { required }\end{array}$ \\
\hline
\end{tabular}

It mainly consists of an inlet (I), a centrifugal air compressor (CAC), a combustion chamber (CC), gas turbine (GT), Free Turbine (FT) and Exhaust diffuser (ED). The working fluid and its path are numbered for modelling purposes at the inlet and exit. The micro gas turbine functions as Brayton cycle law of thermodynamics. In theoretical model, compression of the air occurs in ideal condition and combustion occurs at ideally constant pressure. An off-design condition mitigates the mentioned error. The hot fluid passes to the turbine inlet and expands adiabatically extracting work output. In the Off-design conditions three parameters are considered there are loss due to friction, formation of working fluid turbulence and fluctuation of constant pressure at the combustion chamber. The free turbine is directly connected to a power generator.

There are following Advantages and disadvantages of using axial flow compressors compared to the centrifugal flow compressors are as follows,

- The Axial compressors are less efficient at low rate of mass flow at inlet this allows to handle smaller flow rate efficiently and are commonly used in smaller engines.

- The Axial compressors are expensive to manufacture and has potential vulnerabilities to damage 
caused by foreign bodies. This allows to the centrifugal compressor to perform better in the parameters of resistance and less susceptible to wear and tear.

- The Centrifugal compressor results in shorter length than an equivalent axial compressor due to the fact that centrifugal compressor could produce high-pressure ratio per stage compared to the axial flow compressor.

- At a fixed rotational speed of the compressor, the Centrifugal compressor can operate efficiently at various mass flow rate than the axial compressor.

- Performance losses due to contaminants of deposits on the blade surface of the compressors is less in centrifugal compressor than the axial flow compressor.

- The centrifugal compressor has low frictional parts thus less maintenance compared to the axial flow compressor.

The power generator also known as electrical generator comprises of a device that converts mechanical energy from an external source such as free turbine rotation to electrical energy charging the batteries. The generator is not used to create energy but converts the force in motion to electrical charges. The process is done with a help of conducting wire windings and magnets also based on the principle of electromagnetic induction. The electromagnetic induction states that flow of electric charges is induced when a conductor moves inside a magnetic field. [6]

The generator's interior components, including the stator and the rotor, work in combination to generate electricity by generating movement between the magnetic and electric fields. The stator is a stationary component that contains a set of wires wound in coils around an iron core. The rotor or armature, connected to the output crankshaft of the engine, produces the rotating magnetic field. The rotor generates a moving magnetic field around the stator, which induces a difference between the windings of the stator. A specific output voltage of the generator can be produced by varying the winding patterns. This produces alternating current (AC).

The important factors to be noted from the generator, it can produce amount of tremendous heat and requires a constant cooling system to protect the generator from damages. The generator cooling system considered to be critical they could be used as

1. Pre-heater for inlet air after compressor stage,

2. Pre- heater for fuel to be pumped into the combustion chamber or

3. A bypass bleed inlet for an air cooling system.

All the above three solutions were considered and overall thermal efficiency were studied. The third solution inlet bleed system considered to be best solution as it was found the small generator could not reject heat efficiently. A mix of bypass bleed and fuel cooling system was found to be optimum. The fuel cooling system has to be done without any external pump system as it would increase the mass of the system reducing the overall efficiency.

The station numbering process helps in understanding the thermodynamic cycle of the engine in the Brayton cycle is clearer. The process on the $\mathrm{p}-\mathrm{V}$ or $\mathrm{T}-\mathrm{s}$ diagram should be numbered as described in the station numbering system. The gas turbine, for avoiding complexity in Gas turbine design it is necessary to be represented in schematics for simplified understandings. The schematic of our engine is represented in figure 2. [7]

Table 3. Gas turbine power plant station numbering.

\begin{tabular}{|c|c|}
\hline $\begin{array}{c}\text { Engine Station } \\
\text { Numbering }\end{array}$ & Nomenclature \\
\hline 0 & Conditions in free stream \\
\hline 1 & Engine intake front flange \\
\hline 2 & Centrifugal compressor face \\
\hline 3 & Compressor exit \\
\hline 3.5 & Combustor inlet \\
\hline 4 & Combustor exit/ Turbine inlet \\
\hline 4.5 & Free turbine inlet \\
\hline 5 & Free turbine exit \\
\hline 9 & Exhaust diffuser exit plane \\
\hline
\end{tabular}

The parts of the engine on schematic needed to be cocoordinated for representing corresponding parts to all the designers, suppliers and for conducting tests. To reduce the complexity in understanding aircraft propulsion engineers, assign station numbers. The labelling of stations is as follows, The Free stream conditions are numbered 0 , the entrance to the Inlet of the engine as station 1. The exit of the inlet/inlet to compressor numbered as station 2. The compressor exit /combustion chamber entry are numbered as station 3 . The combustion chamber exit / Turbine entrance is numbered as station 4 . The turbine exit is numbered as 5 . Nozzle Downstream of the throat is numbered as 9 . In our methodologies the numbering systems are tabulated in table 3 .

\section{Engine input parameters.}

The ambient parameter, used are globally accepted standard at sea level data gathered from the ISO standards 3977-2, the ISO ambient conditions for the industrial gas turbine. These data and information involves with density of the air. Any deviation in the standards of the ISO would have impact on the density of the air. This would affect the results due to the change in the mass flow rate, the amount of air that enters the gas turbine system.

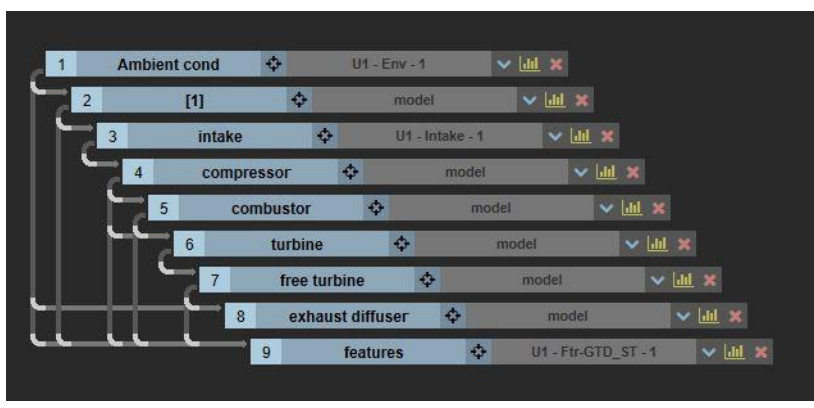

Figure 3. The model of the gas turbine powerplant as implemented in the software to provide staging parameters in accordance with the international standard. is shown from Russian modelling system. 
Table 4. Engine input parameters.

\begin{tabular}{|c|c|}
\hline Parameters & Values \\
\hline $\begin{array}{l}\text { The coefficient of recovery of the total } \\
\text { pressure at the inlet. }\end{array}$ & 0.99 \\
\hline Compressor type & Centrifugal \\
\hline $\begin{array}{l}\text { Relative current density in the cross } \\
\text { section at the inlet to the compressor. }\end{array}$ & 0.75 \\
\hline $\begin{array}{l}\text { The base value of the polytropic } \\
\text { efficiency of the compressor. }\end{array}$ & 0.86 \\
\hline Overall pressure ratio of the compressor. & 3 \\
\hline Stagnation temperature at turbine inlet. & $1500 \mathrm{~K}$ \\
\hline Fuel injection temperature. & $293.15 \mathrm{~K}$ \\
\hline Composition and properties of fuel. & Kerosene $\mathrm{T} 1$ \\
\hline Combustion efficiency ratio. & 0.98 \\
\hline Turbine Type. & Axial \\
\hline $\begin{array}{c}\text { The basic value of the isentropic } \\
\text { efficiency of the compressor loaded } \\
\text { turbine. }\end{array}$ & 0.91 \\
\hline $\begin{array}{l}\text { The basic value of the isentropic } \\
\text { efficiency of the compressor free turbine. }\end{array}$ & 0.91 \\
\hline $\begin{array}{l}\text { Excess power capacity on the rotor shaft } \\
\text { for generator output. }\end{array}$ & $8 \mathrm{~kW}$ \\
\hline $\begin{array}{l}\text { The design value of the available pressure } \\
\text { reduction at the output. ( } \Pi\{c \text {.p }\})\end{array}$ & 1.05 \\
\hline Rate factor (diffuser) $\varphi\{c\}$ & 0.5 \\
\hline
\end{tabular}

\section{Methodologies of parametric analysis}

The research focuses on improving overall efficiency thus a priority parameter. The overall energy consumption required to deliver the cargo of $200 \mathrm{Kg}$ to a distance of $300 \mathrm{~km}$ at a lift altitude of $5 \mathrm{~km}$. The numbers and calculations in this preliminary study has been restricted to theoretical value at sea level. Also, no such research been conducted or reported thus conforming to the novel approach of using Gas turbine powered heavy lift multicopters. The overall efficiency here denotes conversion of power to both mechanical and electrical output for achieving optimum power to mass/volume ratio. Two shafts one holding the Gas generator (that bears the Compressor and high-speed turbine) and the second the free turbine connected to generator. The free turbine uses separate shaft to increase the flexibility usage of controlling power based on fluctuating output requirements.

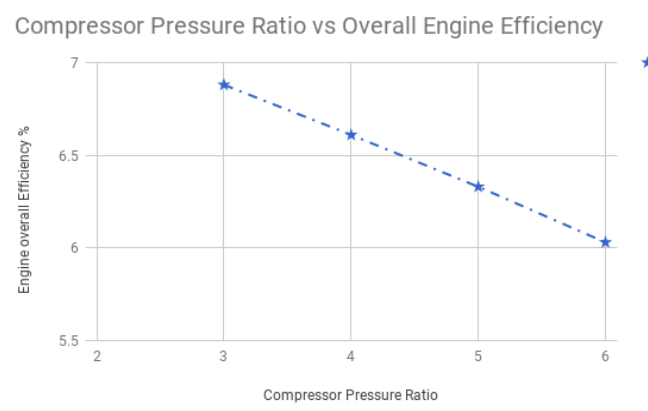

Figure 4. There is decrease in overall efficiency with the increase in pressure ratio.
The preliminarily conditions yielded results for iterations. The initial conditions found out that the system overall efficiency approximated to be $6.37 \%$ at a compressor pressure ratio of 5 , a very low combustion temperature was required at $1087 \mathrm{~K}$. The specific fuel consumption was $1,3176 \mathrm{~kg} / \mathrm{kWh}$ the exhaust temperature calculated to be $841,56 \mathrm{k}$ with a mass flow rate of $0,141 \mathrm{~kg} / \mathrm{s}$.

Before performing any analysis, the results are evaluated based on how various parameters changes with given initial conditions. The studies are performed how pressure ratio changes corresponding with Turbine Inlet Temperature, Overall efficiency and Inlet ambient conditions. Fig 4, 5 and 6 represents the interrelation with fixed parameters.

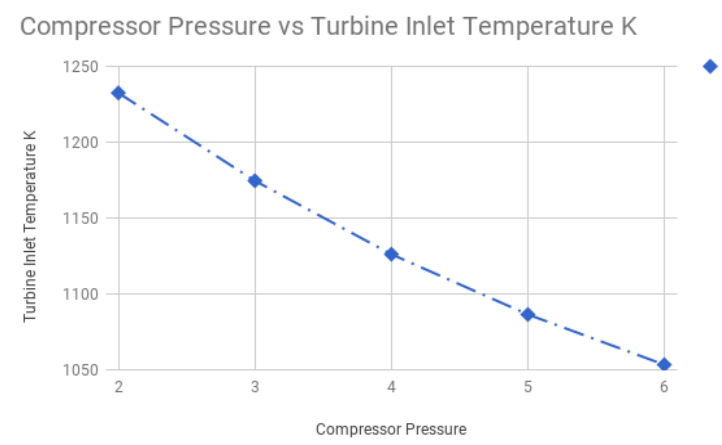

Figure 5. Higher Pressure ratio is required for lower turbine inlet temperature.

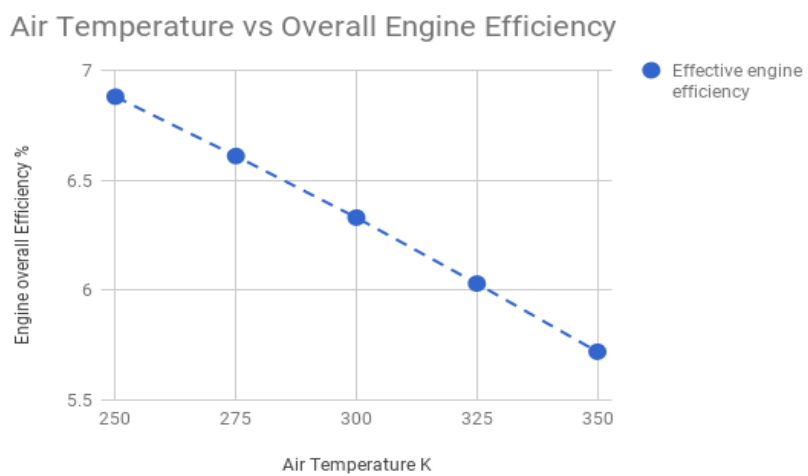

Figure 6. Lower ambient condition results in high efficiency engine, thus requires the need for a pre cooler before the compressor stage.

These interactions of Temperature inlet to the engine, Temperature inlet to turbine, Compressor Pressure ratio and Overall efficiency help us to model the performance of the engine in the software ASTRA. The following graphs represented in fig 7 and 8 helps in calculating the value using first iterations and optimization yielded and results represented in the following table 5 .

Table 5. Preliminary iterations.

\begin{tabular}{|c|c|}
\hline Constant Pressure ratio @ $\boldsymbol{\Pi} *\{\mathbf{K}\}=\mathbf{3}$ & Conversion \\
\hline$\eta\{\mathrm{e}\} @ 1000(\mathrm{TiT})$ & $7.6 \%$ \\
\hline$\eta\{\mathrm{e}\} @ 1100(\mathrm{TiT})$ & $7.7 \%$ \\
\hline$\eta\{\mathrm{e}\} @ 1200(\mathrm{TiT})$ & $7.7 \%$ \\
\hline
\end{tabular}


The Turbine inlet temperature, with respect to overall efficiency has an optimum value of $1000 \mathrm{~K}$ for $7.6 \%$. Meeting our requirements of minimum TiT value. Reported results increase in efficiency from $6.37 \%$ to $7.6 \%$ with a decrease in pressure ratio from the value 5 to 3 .

Now that the pressure ratio, Temperature required at combustion and the required efficiency are identified in cloud patterns. The process is repeated with the final iterations assuming the following values Pressure Ratio $=3$, Turbine inlet Temperature $=1000-1100 \mathrm{~K}$ and required efficiency $=7.5 \%-8 \%$. The specific fuel minimum consumption at above requirements are investigated. The fig: 8 shows the level that is optimized.

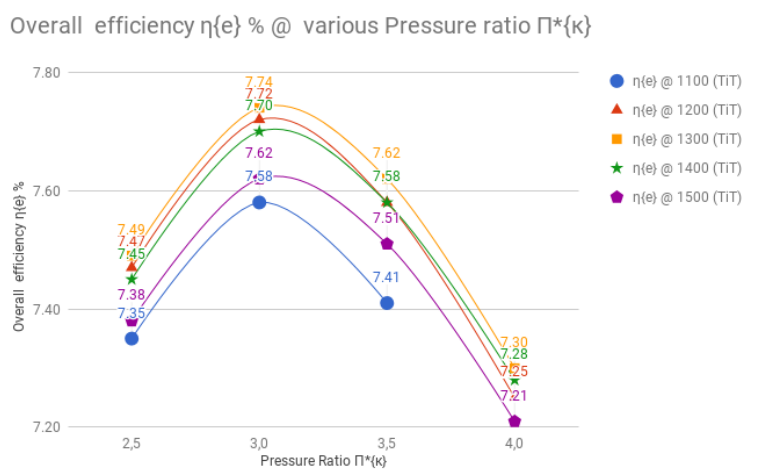

Figure 7. The Parametric initial condition with respective to overall model of the gas turbine power plant represented graphically with zoomed up values. The turbine inlet temperature (TiT) expressed in $\mathrm{K}$.

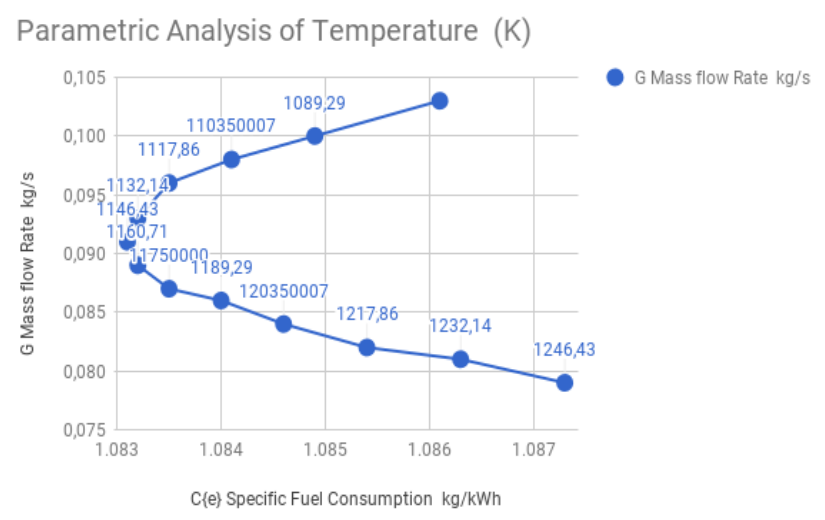

Figure 8. The least specific fuel consumption corresponding to Turbine Inlet Temperature $\mathrm{K}$ along the Mass flow rate of working fluid $\mathrm{Kg} / \mathrm{s}$, viewed in this figure.

\section{Thermodynamics analysis results}

Thermodynamic parameters and analyze the performances of the gas turbine conducted results showing for every $15 \mathrm{~K}$ change in the temperature of turbine inlet temperature there is a change in 0.025 specific fuel consumption approximately. Every increase in the turbine inlet temperature of $15 \mathrm{~K}$, found to decrease $0.15 \%$ in overall efficiency after it hits peak value of $1178 \mathrm{~K}$.

The thermodynamic parameters included compression ratio, ambient temperature, ambient pressure, humidity, heat rate, turbine inlet temperature, specific fuel consumption, air to fuel ratio, component efficiency.

The Efficiency ratio of 1) Net Gas turbine output work ratio (Both Turbine + Free turbine) with 2) Compressor work input ratio improved than the preliminary conditions in this parametric analysis and optimization.

The firing temperature also known as the turbine inlet temperature (TiT), has to be low but highly efficient enough to extract work from the both the turbines. The value of optimized TiT equals $1146 \mathrm{~K}$ with $0.092 \mathrm{~kg} / \mathrm{s}$ Mass flow rate at a specific fuel consumption of less than $1.084 \mathrm{~kg} / \mathrm{kWh}$.

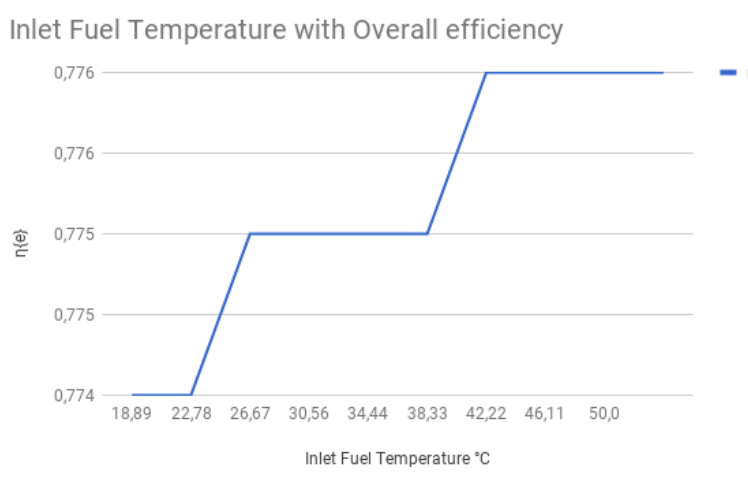

Figure 9. The efficiency increase is noticed using a combined cycle plant. This graph shows the use of waste heat to pre heat the fuel before entering the combustion chamber.

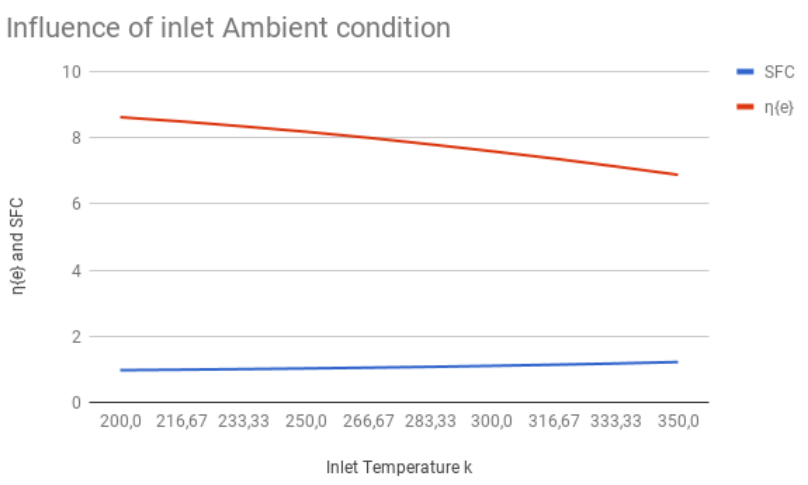

Figure 10. The efficiency increase is noticed using a combined cycle plant. This graph shows the use of external cooling system to the ambient temperature at the inlet of the power plant.

\section{Conclusion}

The working pressure ratio of the turbine drops significantly in proportion with the drop in either combustion chamber or turbine and in both simultaneously. The increase in the turbine inlet temperature increases the Gas turbine overall efficiency, until $1200 \mathrm{~K}$ however the wastage of the heat energy also increases. Hence, a combined power plant reduces these losses by converting the heat to improve the work output of turbines as shown in figure 10. A further study is required to see the percentage of improvement of using waste heat for heating working fluid before the 
combustion stage. A recommendation of bypass bleed airflow used to rotate the free turbine reduces the thermal efficiency and reduces the fuel consumption of the power plant.

The materials used for producing the components of combustion chamber and blades of turbines have limited yield, however, the $1167 \mathrm{~K}$ at Turbine inlet Temperature is within the desired level, thus reducing the cost of manufacturing with readily available materials. The need for turbine blade cooling systems and high temperature resisting super alloys are not necessary. The increase in TiT does not increase the thermal efficiency of the gas turbine after the peak temperature of $1300 \mathrm{k}$.

The decrease in the work power of compressor produces huge positive impact on the output of free turbine. The free turbine output increased with the decrease in the compressor power. The exhaust gas temperature at the diffuser increases significantly the thermal efficiency of the gas turbine. The mass flow rate of the inlet air increases the output power of the free turbine that increases the loss in thermal efficiency. The decrease in pressure at the exhaust duct increases the overall cycle efficiency of the gas turbine. The compressor's inlet pressure ratio and the exit pressure ration of the compressor increases the gas turbine efficiency in both cases. Thermodynamic parameters and performances when analysed produced results showing for every $15 \mathrm{~K}$ change in the temperature of turbine inlet temperature there is a change in 0.025 of specific fuel consumption approximately. Every increase in the turbine inlet temperature of $15 \mathrm{~K}$, found to decrease $0.15 \%$ in overall efficiency after it hits peak value of $1178 \mathrm{~K}$.

Table 6. Gas turbine preliminary iterations for mass estimation

\begin{tabular}{|c|c|}
\hline Specification & Value \\
\hline Output Power & $\begin{array}{c}8.0 \mathrm{~kW} \\
\text { (2 times the peak } \\
\text { specification of the motor) }\end{array}$ \\
\hline Mass & $7.5 \mathrm{~kg}$ including invertor \\
\hline $\begin{array}{c}\text { Fuel } \\
\text { consumption }\end{array}$ & $200 \mathrm{ml}$ per min. (full load). \\
\hline
\end{tabular}

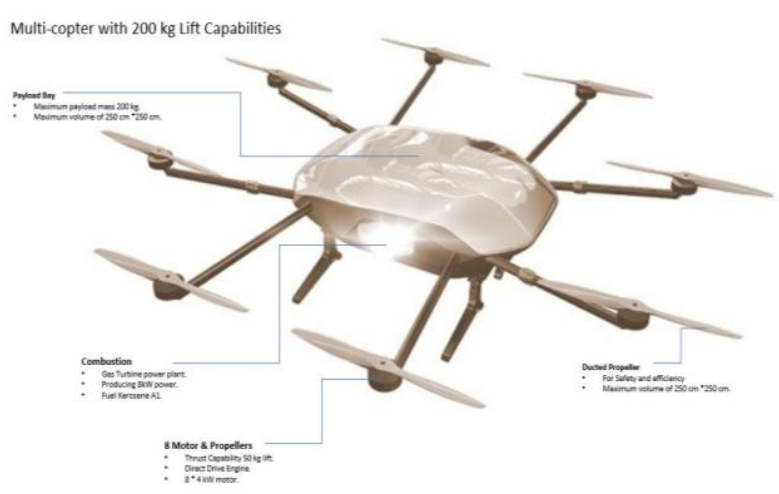

Figure 11. Multicopter with gas turbine powerplant produces output power of $7 \mathrm{~kW}$ electrical power to electrical rotors to provide lift. The picture is only viewing representation for the reader.

\section{Acknowledgment}

The Ministry of education and science of the Russian Federation in the framework for implementation of the Program for increasing the competitiveness of Samara University among the world leading scientific and educational centres for 2013-2020 years supported this work.

\section{References}

1. A.Y. Tkachenko et all, Gas Turbine Engine Optimization at Conceptual Designing. MATEC Web Conf., (2016)

2. Lingen, C., Bo, Y. and Fengrui, S. International journal of Energy and environment, 2 (11) : 199-210, (2011)

3. Maria, J. and, Jinyue Y, Energy, 30 1013-1078 (2005).

4. Franco A, Russo, Int J Therm Sci, 41 843-59. (2002)

5. P. J. Scanlon, R. N. Henriksen, and J. R. Allen, American J of Phys 37:7, 698-708 (1969).

6. Boucher, M. Engineering Evolved: Getting Mechatronics Performance Right the First Time. Aberdeen Group: November (2008)

7. Jeffryes W. Chapman, Thomas M. Lavelle and Jonathan S, NASA/TM 2016-219147, October (2016) 